\title{
SOCIABILITAT I PROJECCIÓ POÈTICA: VEUS DE DONES EN ELS CERTÀMENS LITERARIS BARROCS*
}

\section{SOCIABILITY AND POETIC PROJECTION: WOMEN'S VOICES IN BAROQUE POETRY CONTESTS}

\author{
Verònica Zaragoza Gómez \\ Universitat de València \\ veronica.zaragoza@uv.es
}

Resum: L'objectiu d'aquest treball és mostrar una tradició poètica femenina de certamen que ha perviscut al llarg dels segles, tot centrant-nos en el moment de màxim esplendor, el Barroc. La nostra intenció és visibilitzar aquest focus de difusió des de la perspectiva de la creació i la circulació d'alguns dels primers textos impresos atribuïts a les dones en la història de les nostres lletres, amb poesia tant en llengua catalana i castellana com — molt escassament— llatina. Per fer-ho, després d'haver dut a terme una recerca exhaustiva sobre l'univers dels certàmens dels segles XVI-XVII, i de sistematitzar-ne la producció, oferim algunes observacions de caire sociològic i literari relacionades amb l'origen social de les autores, i el paper i les motivacions d'aquesta participació femenina.

Paraules clau: literatura barroca, certàmens poètics del domini lingüístic català, escriptura de dones, espais de sociabilitat femenina.

Abstract: The aim of this paper is to show a tradition of feminine poetry that has survived throughout the centuries, focusing on the greatest period of splendor, the Baroque era. Our goal is to shed light on this space for literary creation from the perspective of the dissemination of some of the first printed works attributed to women in the history of our literature, which were written in Catalan, Castilian and Latin. To do this, after having carried out an exhaustive search on the universe of the contests of the I6th-I7th centuries and systematising this production, we offer

$\left(^{*}\right)$ Aquest estudi s'inscriu en el projecte d'investigació FFI2015-70095-P finançat per MINECO. Quant a la transcripció dels textos, hem respectat l'ortografia del model exceptuant-ne l'ús de $j / i$ i $u / v$, l'accentuació, la puntuació i l'ús de majúscules i minúscules, que han estat regularitzats segons els criteris actuals. 
Verònica Zaragoza Gómez

Sociabilitat i projecció poètica: veus de dones en els certàmens literaris barrocs

some sociological and literary observations related to the social origin of women authors, and the role and motivations of female participation.

Key words: Baroque literature, poetry contests of the Catalan linguistic domain, women's writing, spaces of female sociability.

es es es

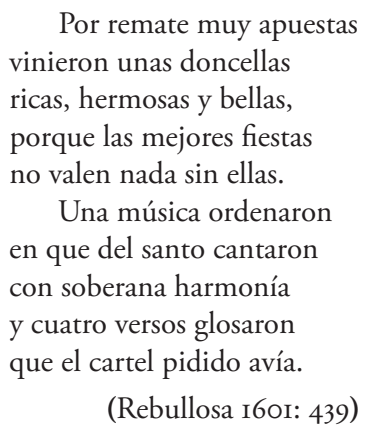

Aquest fragment sobre un certamen literari barceloní de principis del sis-cents dóna una idea prou nítida sobre l'assistència de dames en els esdeveniments urbans que millor van contribuir a la cultura barroca, en l'esplendor de les festivitats civils i religioses. Jordi Rubió s'hi havia referit com a «solemnitat que se sostenia i es justificava amb el seu propi prestigi», i que al segle XVII es converteix «en un número més d'un programa de festes i es combina amb tota la barroca escenografia de què aquelles s'envoltaven» (I985: I2I). Basats en la declamació pública de poemes i la concessió de premis i amb llarga tradició al nostre domini lingüístic, ${ }^{1}$ els certàmens van acabar esdevenint un ingredient més en l'engranatge festiu, que convertia, a la fi, les ciutats en grans teatres «en cuyo escenario, ricamente engalanado [...] los actores (la sociedad urbana y sus gobernantes) representan una función a través del ceremonial con la finalidad de mostrar públicamente su poder, de expresar y difundir su ideología» (Monteagudo 2004: 323). A diferència de les estructures de participació restringides de les acadèmies literàries, la crida presumptament indiscriminada dels certàmens va possibilitar la irrupció de figures autorials femenines, amb peces aportades a la devoció o a concurs.

I, tot això, en un moment en què les demostracions intel.lectuals de les dones eren sancionades, encara més si es feien impúdicament públiques, en una societat misògina

I. Comptem amb treballs fonamentals de Ferrando (1983); Rossich (2003 i 2006) o Mas i Usó (2009). 
com la de l'Antic Règim. Així doncs, mentre que l'ambient sociocultural de l'època els comportava problemes per a autoritzar-se com a emissores culturals, l'univers de certàmens els va possibilitar l'assumpció d'un paper creador actiu, així com la visibilitat social de la seua obra, tant per la via de la poesia pública (aportada als certàmens) com per la de la poesia publicada (impresa en relacions de festes). ${ }^{2}$ Fins al punt que, en les lletres catalanes, les rúbriques femenines en poesia impresa s'hi materialitzen en bona part amb aquest corrent de poesia social i urbana de circumstàncies, transmesa per les extenses relacions festives; ${ }^{3}$ una constatació que coincideix en altres illots geogràfics peninsulars (Baranda 2004 i 2005: 217-244; Marín 2013; Martos 20174). En general, es tracta d'autores ocasionals de les quals ho desconeixem gairebé tot, oblidades més enllà d'alguna menció aïllada i una discreta activitat poètica apuntada anecdòticament per la crítica, ${ }^{5}$ sense un afany d'abordatge exhaustiu.

L'objectiu d'aquest treball és, doncs, mostrar una tradició poètica femenina de certamen que ha pervingut al llarg dels segles, tot centrant-nos en el moment de màxim esplendor, el Barroc. Des de la perspectiva de la creació i recepció dels primers textos impresos de dones en la història de les nostres lletres (en català, castellà $\mathrm{i}$ llatí), pretenem visibilitzar aquest focus de difusió, aportant també observacions de caire socioliteràries, sobre l'origen social de les autores, i el paper i les motivacions d'aquestes participacions.

\section{ELS CERTÀMENS LITERARIS, APARADORS DE POESIA FEMENINA}

Generalment, un prejudici latent havia marcatl'estudi de la literatura de certamen, considerada d'escàs interés estètic i menyspreada per ésser considerada «rutinària i banal» (Rossich 2006: 63, i també 2003: 93). Recentment, però, aquesta parcel.la cultural s'ha vist beneficiada especialment pel desvetllament de l'entramat festiu de l'època (Pedraza 1982; Mínguez, González \& Rodríguez 2010; García Espuche et al. 2010).

2. Manegem aquí els conceptes de Ruiz Pérez (20II: 383).

3. Hem editat i estudiat tots aquests testimonis a la nostra tesi doctoral (Zaragoza 20I6).

4. Agraïm a l'autora l'enviament del seu treball.

5. Segons Rubió i Balaguer, «no mancaren dames ni religioses a la cita» (1985: I29) en alguns certàmens de Catalunya; presència apuntada també per Rossich (2003) en els certàmens de Barcelona, i per Ferrando (1983) en els de València. Així mateix, Joaquim Riera i Bertran apuntava per al Certamen literario, celebrat per l'Asociación Literaria de Gerona el I872, el triomf d'una dama en un dels dos certàmens precedents, del segle XVII, i remarcava que «en el segundo tomaron parte varias damas gerundenses [...]; mostrando así que el amor a las letras no era en la Gerona de entonces, como no lo es hoy, patrimonio exclusivo de hombres» (Asociación I872: 28).

Caplletra 65 (Tardor, 2018), pp. 15-41 
Verònica Zaragoza Gómez

Sociabilitat i projecció poètica: veus de dones en els certàmens literaris barrocs

En l'àmbit literari, també hem assistit a un canvi en la mirada de l'historiador: no podem obviar que els poetes més destacats del moment van fer cap en aquests espais que, alhora que els permetien inserir-se en els "parnassos» locals, els oferien la possibilitat d'assajar l'estil i la forma de la seua escriptura, per tal com «L'objectiu dels certàmens no és fer que sorgeixi un poeta genial, sinó ensenyar les persones cultes, els literats, a fer poesies ben fetes. La seua finalitat és perpetuar i afavorir la creació poètica..." (Rossich 2006: 69-70). Aquesta idea permet plantejar el significat de la concurrència de dones també en termes didàctics: les dones que s'emparassen en aquelles convocatòries podrien aspirar a cercar-hi el rigor poètic; a experimentar, segons unes regles prefixades, el procés d'escriptura poètica. Fos com fos, en aquests espais les poetes van poder expressar-se públicament, vincular el seu nom a l'acte de creació poètica i participar-hi "per la seducció del prestigi social que comportava el fet de guanyar-lo o d'alternar amb les principals figures de la vida literària local» (Ferrando 1983: 137) ${ }^{6}$

\section{LES DONES EN ELS CERTÀMENS DELS SEGLES XVI-XVII: L'ESTABLI- MENT D'UN CÀNON EPOCAL D'ESCRIPTURA I ERUDICIÓ FEMENINES}

2.I. SOR BERNARDA ROMERO I LES JUSTES DE BERNAT CATALÀ DE VALERIOLA (C. I 592-I 593)

Els primers certàmens on advertim la presència d'una dona són dos dels tres sufragats per Bernat Català de Valeriola, president fundador de l'Academia de los Nocturnos (I59I-I594). La cistercenca sor Bernarda Romero (València, a. I592-I62I) aportà dues peces a la primera festa poètica (c. 1592) celebrada en el seu convent mateix, el de Nostra Senyora de Gratia Dei o de la Saïdia de València. Uns versos que li van fer merèixer un segon premi, amb la reputació que «hallaron muy en su puesto / lenguage, concepto y arte» (Justas I602: 200). Malgrat que no podem obviar que el guardó podria respondre a una deferència vers el convent amfitrió, amb el prestigi cultural que li podia projectar, el premi degué esperonar sor Bernarda a enviar una nova peça — no conservada - al tercer dels certàmens de Valeriola, el 1593. De fet, aquesta activitat poètica de la cistercenca ha dut la crítica a incloure-la en el cenacle dels Nocturnos, però més aviat es tractaria d'una participació als certàmens, als quals també van acudir alguns dels poetes autoritzats a assistir regularment a aquelles tertúlies nocturnes: cavallers, membres de l'alta burgesia i del clergat.

6. De fet, trobem una peça amb veu femenina en les Obres o Trobes en lahors de la Verge Maria (I474). 


\subsection{LLOANCES POÈTIQUES PER L'ELEVACIÓ DE BEATS I SANTS}

\section{A la canonització de Ramon de Penyafort (Barcelona, I60I i I626; València, I602)}

Entrats ja al segle XviI, el grau de participació popular a les festes de Barcelona per la notícia de canonització del dominic Ramon de Penyafort va ser tan elevat que «la finalitat inicial va quedar superada per la mateixa marxa festiva de les coses» (Garcia Espuche 20I0: 35). De fet, s'hi nota un destacat protagonisme femení en les diverses jornades de la festa (Zaragoza 2017) i en els dos certàmens que completaren l'aparat festiu: en el primer dels concursos, una religiosa anònima es va emportar un premi, lloada per la "humildad de espíritu» (Rebullosa I6or: 392), mentre que en la Justa literaria de l'Estudi General, hi comparegué Caterina de Cardona, de llinatge bo i distingit a la Catalunya moderna. És presentada «[...] entre famosas, famosa» $\mathrm{i}$ "[...] en saber peregrina, / sabia en estremo y tan diestra /que es de las dotas maestra» (Rebullosa I6or: 439), tot encapçalant un tropell de fins a nou dames més que haurien aportat distinció a la festa — sense obra conservada. En efecte, els versos amb què hem inaugurat el treball ens proporcionen una interessant lectura, en clau sociològica, amb la referència a les «doncellas / ricas, hermosas y bellas», glossadores de versos. ${ }^{7}$ Llur intrusió en el camp literari quedava legitimada pels objectius del certamen, l'expressió de devoció al sant, que els oferia també un espai per a socialitzar-se:

Tras quien mil hermosas damas
estas fiestas celebraron
y aunque premios no llevaron
de su valor muchas famas
con ser una despertaron.

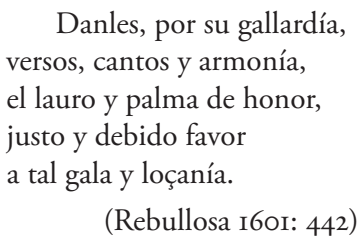

Un any més tard, sor Bernarda Romero apareix com a única representant femenina del certamen amb què València va aplaudir la mateixa canonització (I602), on el «concurso de toda la nobleza de la ciudad y otra gente fue tanto que parecía impossible poderse oýr nada» (Gómez I602: 396). Amb dues peces aportades, la religiosa hi competeix amb una cinquantena de poetes congregats, alguns dels quals són figures destacades en l'ambient literari de l'època: Carles Boïl, Gaspar Mercader, Guillem de Castro, Gaspar Gil Polo... I hi va resultar guanyadora d'un segon premi.

7. Posteriorment, són identificades de manera imprecisa i amb els cognoms feminitzats: Figuerola (llinatge Figueró?), Ollera (Oller?), Boscana (Boscà o Bosc?), Leonarda, nimfa Astora, Alburquerque, Jori, Fontelles...

Caplletra 65 (Tardor, 2018), pp. 15-41 
Verònica Zaragoza Gómez

Sociabilitat i projecció poètica: veus de dones en els certàmens literaris barrocs

La conservació d'una sentència acèfala ${ }^{8}$ permet documentar, encara, la celebració a Barcelona d'un certamen per al mateix sant, el I626. La representació d'una bona nòmina femenina ${ }^{9}$ evidencia que la presència de dones poetes s'estava convertint en un fenomen creixent. Allò que ha estat considerat com el «dernier cri del esnobismo literario» (Baranda 2005: 22I) a Madrid, on els organitzadors dels certàmens reclamaven, cada vegada més, contribucions poètiques femenines i es requerien versos signats per dones per als preliminars d'impresos, ${ }^{10}$ es començava a registrar amb la mateixa intensitat també al nostre domini lingüístic.

A la devoció de fra Domingo Anadó (València, 1606) i a la beatificació de fra Lluís Bertran (València, I608)

A la València de principi de segle el testimoniatge femení continuava limitant-se a la ploma de sor Bernarda Romero: el I606, va brillar amb un primer guardó entre la vintena escassa de poetes que es van presentar al certamen de les festes a la devoció del dominic local fra Domingo Anadó (Gómez i607). Dos anys més tard, el I608, la religiosa tornava a fer acte de presència en la festa poètica per a la beatificació d'un altre sant local, el dominic fra Lluís Bertran (Aguilar 1608; Gómez i609). El certamen va reunir el bo i millor dels poetes del Túria: «Uvo una divina competencia entre las sabias musas y los regaladíssimos orfeos, que resultó en mucha honra del santo y dio extraordinario gusto a los oyentes» (Gómez I609: 145). En total: una cinquantena de poetes, entre els quals cinc «sabias musas». Una xifra que pot semblar escassa però que revela un protagonisme creixent de les dones. Al costat de la infatigable sor Bernarda Romero, hi trobem una dama amb identitat velada, ${ }^{11}$ la dominica del convent de Santa Caterina de Sena sor Àngela Sànchez, i les «donzellas» Esperança i Bàrbara Abarca,

8. Conservada al ms. Recreo i jardí del Parnàs i muses catalanes de Baptista Mirambell, Biblioteca de Catalunya, Ms. 1358, f. 273-28r. Sobre aquest certamen, se'n va imprimir la sentència amb l'única obra publicada, els versos graciosos de Pere Antoni Jofreu (Felices de Cáceres I626).

9. Alguns noms de la sentència que es poden atribuir a figures autorials reals són Jerònima Castro, Leticia Pibernat, Alexandra Leòncia Izquierdo (o Esquerdo), Maria d'Henares, Maria Pallarols, Lluïsa Henares i, les guanyadores, Isabel Margarit, Maria d'Aguiló, Magdalena Serra i Petronila de Lobera. D’aquestes, en destaquem Alexandra L., procedent de Lleida, que identifiquem amb una filla de Pere Joan Esquerdo, besavi de l'erudit valencià Onofre Esquerdo Sapena (I635-I699).

Io. Lope de Vega va ser un dels primers a incloure peces femenines en els seus impresos: Arcadia (I598), El Isidro (I599), La hermosura de Angélica (I602), El peregrino en su patria (I604) o les Rimas (I6I4).

II. Caldria esbrinar la relació entre aquesta i una «dama devota» anònima, que havia manifestat devoció al sant amb un cant poètic interpolat en la Primera parte de la historia del bienaventurado padre fray Luys Bertrán (I584) (Zaragoza [en premsa]). 
germanes. Pels detalls biogràfics exhumats d'aquesta darrera, criada d'Inés Pujades, sabem que va gaudir d'una reputació social i espiritual vinculada, precisament, amb el carisma del beat aplaudit: fou una coneguda devota del sant per mitjà de la qual va obrar alguns miracles (Saborit I651: 270, 430, 43I).

\section{A la beatificació i canonització de Teresa de Jesús (València, I6I4 i I62I; Barcelona, I6I4)}

Una de les efemèrides que més adhesió va suscitar entre les dones va ser la beatificació de Teresa de Jesús, el I6I4, celebrada amb nombrosos festejos a la península (Diego de San José I6I5). De fet, aquest any s'ha considerat un punt d'inflexió en la concurrència femenina en els certàmens peninsulars, per tal com «[...] el ejemplo teresiano sin duda animó a mujeres a escribir y a publicar, en este caso a "hacer públicos" sus versos a través de la lectura oral y/o la letra impresa» (Marín 2013: I49). No podem obviar que la publicació i l'autorització de la seua obra a partir de 1588 havia contribuït a establir-la com a model de dona santa i virtuosament avesada amb la ploma; una influència que també es deixaria sentir en l'augment de visibilitat de les autores del nostre domini lingüístic (Zaragoza 20I5; 20I6).

Si tornem als certàmens esdevinguts al nostre àmbit, per a València, de les tres peces transmeses (Diego de San José i6ıs: f. 44-49v), solament una cançó de sor Jacinta Herèdia ens certifica la concurrència femenina a l'acte, la qual degué ser, per força, més nombrosa si extrapolem la implicació de les dones al mateix certamen de Saragossa (Marín 2013: 162) o al de Barcelona, del mateix any, on recomptem deu autores, entre els seixanta-quatre participants. ${ }^{12}$ En el certamen barceloní es feia palés com aquest espai de sociabilitat es consolidava com a esfera de creació, projecció i visibilitat d'escriptura pública femenina. Les dames participants, totes elles d'origen distingit, són figures vinculades a l'orde carmelità, tot començant per l'esposa del mateix organitzador, protectora dels carmelites descalços de Barcelona, Lucrècia Balcells i Puiggarí (Barcelona, a. I584-1625) o Graïda de Pinós, guanyadora d'un segon premi i retratada com a «sabia», que «sin haber estudiado / se le puede dar el grado / en la escuela salmantina» (Dalmau I6rs: [II], 77). Altres provenen del món conventual barceloní, com sor Elena de Cardona i la jove "participant» ${ }^{13}$ sor Teresa Preixana (i Calvo?) (Barcelona?, c. I602-1677), del convent dels Àngels i Peu de la Creu;

I2. Tres peces de poesia femenina als preliminars del volum amplien la representació autorial de dones. 13. Quin era el veritable interés per fer-la-hi constar amb uns versos vinculats al seu nom, com la coneguda pseudo-Oròsia, joveníssima participant gironina, que veurem més endavant?

Caplletra 65 (Tardor, 2018), pp. 15-41 
Verònica Zaragoza Gómez

Sociabilitat i projecció poètica: veus de dones en els certàmens literaris barrocs

Francesca de Toledo, possiblement del convent de Montsió; Teresa del Calvario’ vinculada hipotèticament amb la caputxina Maria Àngela Astorc, o la religiosa desconeguda, Joana Ferran. I no podien deixar d'assistir-hi altres dames de cognom distingit, com ara Joana o Teresa Enríquez, guanyadora d'un tercer premi; Anna Magdalena de Tamarit i Guardiola, guanyadora d'un primer premi i considerada «alta y divina Thalía, / qual phénix única y sola / entró al declinar del día» (Dalmau i6I5: [II], 77v); o, finalment, Anna Ivorra i Raset (Anna Meca), amb una interessant implicació en el clima festiu i cultural del moment (Zaragoza 20I5: 272-273).

El I62I, la notícia de canonització de Teresa de Jesús, un any més tard, fou festejada a València amb un certamen que va congregar trenta-un poetes, dels més actius del moment, entre els quals cinc dones: una "doña Laura celebrada», que «a muchos hombres excede / con su pluma bien cortada» (Mendoza I622: I63) i quatre religioses, representants d'ordes diferents, que es veieren cridades a cantar a llur mestra espiritual i intel.lectual: sor Bernarda Romero, de conegudíssima fama en aquests espais, la clarissa sor Emerenciana d'Haro, i les carmelites sor Eugènia Pérez —emparentada possiblement amb Jeroni Pérez, un altre participant-i sor Felicitas Amada.

\section{A la beatificació de Tomás de Villanueva (València, I6Ig)}

La notícia de beatificació del sant local i arquebisbe de València, Tomás de Villanueva, va empényer les autoritats civils a dedicar-li el r619 "fiestas por la ciudad, de músicas y bayles, danças, máscaras, e imbenciones de fuegos; [...] muchas luminarias $[\ldots]$ vacando estos tres días los negocios, [...] tres famosas máchinas de fuego en las tres noches; i bravos toros...» (Martínez de la Vega I620: I4). Les celebracions foren rematades amb les invencions poètiques acostumades. Malgrat que la concurrència de les dames en alguns actes d'aquestes festes està ben documentada, ${ }^{14}$ no van escoltar la crida del certamen poètic, ja que en tot l'esquadró dels quaranta-un poetes que «acudieron con gala i ardimiento» (Martínez de la Vega 1620: 469) només advertim la presència de la ja ben coneguda sor Bernarda Romero. Apareix citada al vexamen amb l'acostumat to satíric i un cert punt de malícia quan se'n qüestiona l'autoria i, alhora,

I4. Per als torneigs se'ns diu que «En el tablado de sus ecelencias uvo muchas señoras de título, i en el vario i vistoso ventanage (que es en esta plaça capacísimo) muchas damas i señoras de cuenta, de quién se podía dezir devidamente lo que en otra ocasión dixo nuestro valenciano poeta Gaspar Aguilar en esta otava: "Como las bellas casas del mercado/ todo son ojos para ver las fiestas/ i de paños de seda i de brocado/ están aderezadas i compuestas. / Las damas, es negocio asegurado,/ suelen parecer, estando puestas/ entre tantas riquezas y despojos / ermosas niñas de tan bellos ojos" " (Martínez de la Vega I620: 562-563). 
se’n crítica l'ús de la paraula pública, acte vinculat en la religiosa amb l'ostentació i la vanaglòria:

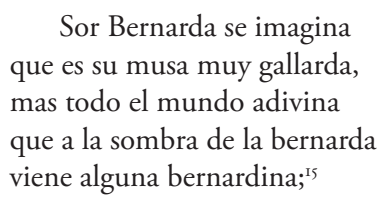

Sor Bernarda se imagina que es su musa muy gallarda, que a la sombra de la bernarda viene alguna bernardina; la vangioria:

\author{
sin duda algún ombre grave \\ con su nombre quiere azer \\ que todo el mundo le alabe. \\ Mas yo quisiera saber \\ lo que él se piensa que sabe. \\ (Martínez de la Vega i620: 546)
}

Aquests versos ens proporcionen una idea bastant clara sobre la recepció d'una autora que s'estava consolidant en aquests espais literaris concorreguts.

\section{A la canonització de sant Isidre, Ignasi de Loiola i Francesc Xavier, i la beatificació de Lluis Gonzaga (Girona, I622)}

El I622, Girona va veure en el marc de la canonització dels sants Isidre Llaurador, Ignasi de Loiola i Francesc Xavier, i la beatificació de Lluís Gonzaga, la major de les oportunitats per a celebrar les que serien les festes poètiques més recordades. Foren organitzades pel matrimoni Martí Sanz de Latrás d'Agullana i Elionor Agullana de Sarriera (hereva de la nissaga noble gironina), promotors de l'establiment dels jesuïtes a la ciutat. Dels cinquanta-dos participants, unes huit dones, emparentades amb els organitzadors i amb el sector més distingit de la societat gironina, prengueren part en el famós certamen, articulat a mode de justa cavalleresca. Els llinatges Sarriera, Xammar, Miquel, Ferrer, Cartellà i Samsó s'hi veieren representats amb la participació de llurs dones. Parlem d'Elvira Sarriera (guanyadora d'un segon premi), filla de Joan de Sarriera-Gurb i Descatllar, batlle general de Catalunya, i cosina d'Elionor d'Agullana (Riquer 1979: 214) (es casaria dos anys després amb Lluís Descatllar i Desbac, significat políticament amb la causa de la Generalitat de Catalunya durant la Guerra dels Segadors); una Maria Llupià, amb tota probabilitat Maria Llupià i de Puig (a. I622-?, I646), descendent de Miquel de Llupià, la qual contrauria matrimoni huit anys després amb Jeroni Ferrer i Real, ciutadà honrat i alferes de la Companyia de Girona durant el setge de Salses (I639) i parent del cronista Jeroni del Real (Busquets I994: I, IO9-IIO), l'esposa del qual, Agnés Miquel Real de Fontclara (Barcelona, a. I619-Girona, I629), filla del cavaller Francesc de Miquel i Copons, també va participar al concorregut

I5. En l'ús col-loquial, bernardina significa 'fanfarronada'. 
Verònica Zaragoza Gómez

Sociabilitat i projecció poètica: veus de dones en els certàmens literaris barrocs

certamen; ${ }^{16}$ o Artemísia Samsó, amb vincles familiars amb els Agullana i emparentada possiblement amb Narcís Samsó i Montpalau, prohom distingit de la ciutat, mestre de camp del rei i sergent major del terç de Girona en la causa antifilipista. El fet que Artemísia en sufragués alguns festejos i hi contribuís a decorar l'escenari festiu («empleó su industria y riqueza en enjoyar la imagen de san Francisco Javier», Ruiz I623: f. 8v) en proven la iniciativa i el paper actiu en diferents sectors de l'organització, en el marc d'uns interessos culturals més amplis que inclourien també el gust per la poesia, com ho demostra el poema aportat al certamen. Maria Samsó, possiblement germana de l'anterior, també hi va aportar una peça a la devoció, com les tres petites Agullana, vinculades al certamen amb edats molt precoces: en el moment en què les peces van ser presentades en concurs amb els seus noms, Magdalena (Girona 1609-?, I669) ${ }^{17}$ tenia solament tretze anys, Francesca (Girona I612-I628), deu, i Oròsia (Girona, c. I6I4-16I5-?, d. I64I), ${ }^{18}$ uns set. Només en aquesta darrera, la crítica ha estat determinant refusant-ne l'autoria per tractar-se d'una autora massa «prematura»; ${ }^{19}$ però, hem d'estendre l'ombra del dubte a la resta d'Agullanes o, inclús, a les participants vinculades amb peces a la devoció? ${ }^{20} \mathrm{Fa}$ de mal de respondre sense cap documentació complementària als poemes impresos al seu nom, l'únic element conservat.

\section{En honor a sant Tomàs (Barcelona, I643)}

Dues dècades després que Girona es vestís de festa, l'acadèmia de Sant Tomàs de Barcelona celebrava un altre certamen en honor al sant homònim (I643). És conegut pel vexamen que el poeta Francesc Fontanella va dedicar-li, amb un interessant elenc de huit dames, de cognoms nobles, presents en la festa poètica: Francesca de Calders (possiblement, religiosa del convent de Santa Maria de Jonqueres de Barcelona), Teresa Alemany (religiosa del monestir de Sant Daniel de Girona), Teresa Ripoll, Eulàlia

I6. Malgrat que s'ha qüestionat l'autoria de la poesia aportada (Busquets I994: I, 72), hem de tenir en compte que Agnés fou una dona de bona família, possiblement amb bon nivell de formació.

17. Casada des de I634 amb Rafael Xammar, i des de 1638, en segones núpcies, amb Juan-Agustín Sanz de Latrás y Gaztelú, comte d'Atarés i senyor de Latrás.

I8. Posteriorment fou religiosa del monestir de Santa Maria de Jonqueres de Barcelona, del qual va eixir per a casar-se amb Josep Galceran de Pinós i Perapertusa, senyor de Santa Maria de Barberà Castlà d'Arraona. Cinc anys després del certamen, fra Martín de la Cruz li adreçava una carta en què li feia saber la seua genealogia familiar (De la Cruz i627: f. 6-8). Oròsia».

19. És l'única dona poeta antologada per Rossich \& Valsalobre (2006: I56-I57), amb el nom de «Pseudo-

20. Les rúbriques d'algunes peces a la devoció ambigüen una autoria difícil d'escatir com en el cas de la glossa atribuïda a Maria Samsó («A la devoción de Maria Sansó») per a qui es fa difícil saber si és una peça a la devoció del sant o bé uns versos a la devoció de la dama, encarregats a un altre autor. 
Camps, Felícia Safont, Anna Maria Barberà, Eleonor Bru i de Granollacs (emparentada amb Francesc Bru i de Granollacs, regent de la tresoreria del Principat de Catalunya), i sor Teodora Molera (guanyadora). Hi són presentades prèviament com a flors que, al-legòricament, fan més agradable l'aparença tètrica i trista de l'hospital de llunàtics, metàfora del grup de poetes congregats, molt comuna al barroc:

$\begin{array}{lcl}\text { [...] viu moltas setmmaneras } & \\ \text { que en aquell jardí ditxós } & 985 & {[\ldots]} \\ \text { de primavera divina } & \text { Però aquellas mi senyoras, } \\ \text { éran soberanas flors. } & \text { per fer-me sensurador, } \\ 945 \quad \text { O era camp aquell portal } & \text { tragueren versos també } \\ \text { en què lo déu del Amor } & \text { que m’admiraren de nou. } \\ \text { per rendir las voluntats } & \text { (Miró ed. I995: 157-I59) } \\ \text { juntava exèrsits de sols. } & \end{array}$

Malgrat l'estimació d'una suposada «representació ben equilibrada de l'un il'altre sexe» (Brown 1987: 194) en aquesta cita, l'eventualitat de la concurrència femenina en esdeveniments culturals d'aquesta mena és ben palesa en l'atribució que fa Fontanella de l'adjectiu «setmaneres» a les dones poetes (s'hi entén per «Persona que exerceix una funció durant una setmana quan li toca per torn», DIEC); un qualificatiu que no vincula, en canvi, a la més famosa novel.lista del Siglo de Oro castellà María de Zayas. Com a participant al mateix certamen, ella apareix citada en el vexamen al costat d'altres homes, amb atributs masculins: «ab cara varonil, / que a bé que sayas tenia, / bigotes filava altius»); distància que revelaria que Zayas ja era una autora consumada i amb una carrera literària consolidada al segle XVII. ${ }^{21}$

\subsection{POESIA COMMEMORATIVA D'ALTRES ESDEVENIMENTS POLÍTICS I RELIGIOSOS}

Institució $i$ revalidació de la Immaculada Concepció (Barcelona, I6I9 i I656; València, I622)

Més enllà de les festivitats promogudes des del centre peninsular o les que cada territori impulsà per als seus aspirants a la santedat, la institució de la Immaculada

2I. Pocs anys després veurien la llum les edicions barcelonines de Novelas amorosas y exemplares en la impremta de Gabriel Nogués (I646) i Parte segunda del sarao y entretenimiento honesto (I649), per Sebastián de Cormellas (aquesta darrera amb l'imprimatur de «Fontanella Regens», conseller en cap de la ciutat, Joan Pere Fontanella, germà gran del poeta). Resulta una línia interessant d'estudi la xarxa de relacions entre «FontanellaMaria de Zayas-Academia de Santo Tomás», apuntada per Brown (1993), qui va conjecturar la residència de l'escriptora a Barcelona el I643. 
Verònica Zaragoza Gómez

Sociabilitat i projecció poètica: veus de dones en els certàmens literaris barrocs

Concepció, discutida teològicament al llarg dels segles i dictada finalment el I6I7 va ser motiu de gran exaltació festiva arreu de la Corona d'Aragó, on se succeïren els festejos i els certàmens poètics. Aquests esdeveniments vingueren acompanyats de publicacions dedicades a fomentar el fervor popular per la causa mariana, defensada per la casa dels Àustria. En aquest context, a Barcelona, el I6rg, la confraria de la Concepció va organitzar un certamen en el marc de les festes convocades el I6I8, arran del decret de jurament de fidelitat de la Universitat (Rossich 2003: I05, n. 97). S'hi van repartir premis a dues poetes: Isabel Boix ${ }^{22} \mathrm{i}$ Adriana Cabanyes i Sinisterra, autora d'una peça en català guardonada "por su ingenio". Ambdues llueixen en un ball de xifres desproporcionat a favor dels homes participants: d'uns quaranta-dos poetes, només cinc són dones comptant-hi les dues guanyadores. Hi apareixen acompanyades de Francesca Escalas [= Escales], Casilda Villalba ${ }^{23}$ i la que signa com a comtessa de Montagut. Aquesta no pot ser una altra que Jerònima Llull i Cabrera (Barcelona, a. I6r8-Soneixa, I649) (o Jerònima Llull de Boixadors), de la flor i nata de la societat barcelonina, la qual mereix un comentari a banda. En casar-se amb Guerau de Cruïlles i Santa Pau, I comte de Montagut i baró de Llagostera, va heretar-ne els béns i la titularitat del comtat que després li seria disputat (Rodríguez Rodríguez 20I2); la conflictivitat política de la Guerra dels Segadors la féu fugir el I64I al palau de Soneixa (Alt Palància) on moriria, tot seguint les passes del seu segon marit, Josep Folc de Cardona i Cardona, partidari de Felip IV. És conegut el paper destacat de l'aristòcrata dama en algunes de les festes patrocinades per l'elit barcelonina, en el cercle de sociabilitat nobiliària més exquisit de l'època (Rodríguez Rodríguez 20I2: I6I-I62; Molas 2004a: 200). Per això, els versos aportats per la comtessa en aquesta ocasió — pels quals Moradell li concedeix «la corona de diamante», en considerar-los «el plato de más gusto /que se ha traýdo a la mesa» (I6I9: f. D7-D7v) — s'han d'entendre com un desig d'aparéixer i fer-se visible com una dona il.lustrada en aquest clima festiu.

El nou decret del 1622 a favor de la declaració del dogma de la Immaculada Concepció va ser aplaudit amb les commemoracions pertinents a València, on la Universitat s'havia posicionat com a ferma defensora immaculista. El mateix I622 un certamen va reunir prohoms destacats, encapçalats pel virrei, els jurats, la noblesa... delerosos d'escoltar els poemes dels vora quaranta-quatre poetes reunits. Entre ells, només una dona: la religiosa desconeguda sor Francesca Sans Navarro (que potser s'ha de posar en relació amb Vicent Sans, un altre participant), dibuixada al vexamen a l'ombra d'un «escriviente bizarro» (Crehuades 1623: 263-264), amb fonament desconegut.

22. Vinculada possiblement amb Pere Boix, doctor en Drets i assessor del General del braç reial. 23. Potser parenta del participant al mateix certamen, Miguel Villalba. 
Hi seguiren altres certàmens immaculistes, amb poques notícies, fins que, el 1656, la Ciutat Comtal va acollir l'acte poètic amb major representació femenina de tot el Barroc, en una clara mixtura del poder reial i religiós. Aquell espai de sociabilitat materialitzava els esforços de la ciutat per aconseguir la sumptuositat que requeria l'ocasió: la promulgació de la festivitat del patronatge de «Nuestra Señora sobre España» en unes festes que representaven alhora la «ideología del poder» (Reza 2008: 773). Hi van acudir poetes catalans i forans, entre els quals llicenciats, doctors religiosos, militars i personatges castellans com «Andrés Mansilla, veedor de viandas, o Juan Antonio González de Garrica, aposentador mayor de la Casa y Camino de Juan de Austria» (Reza 2008: 773), de l'entorn del mateix Joan d'Àustria, espectador insigne d'aquell espectacle. També una bona munió de dames aristòcrates i religioses, esmentades com a participants en igualtat de condicions respecte als homes. Hi van concórrer fins a quinze dones, presents en gairebé totes les categories, excepte en la dels versos llatins:

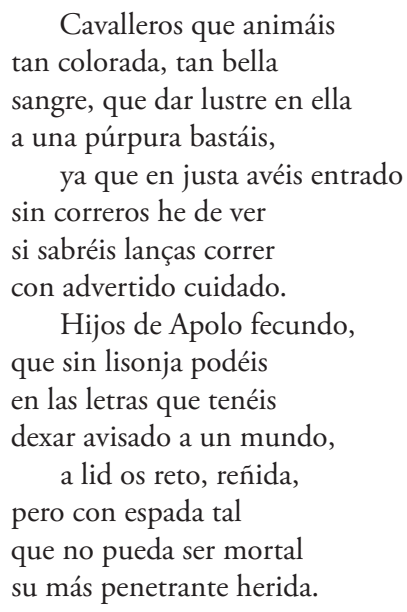

Damas en cuya hermosura tanto el cielo se esmeró que el caudal todo empleó en ellas de su luz pura, conmigo avéis de travar oy certamen competido. Mucho temo ser vencido de un valor tan singular, que con bizarro ademán, con airosa bizarría, haze rostro cada día al poder de un solymán.

(Modolell 1656: I38-I39)

Alguns dels versos pertanyen a Isabel Agnés d'Erill i de Sentmenat (Barcelona, a. 1604-1665), que signa com a comtessa de Guimerà, títol que li fou arrabassat el I662 (Moreno 2002: 27). Dama de reconeguda erudició, va participar de les aficions i els afanys literaris del seu marit, l'erudit Gaspar Galceran de Castre (Barcelona, I584Saragossa, I638), I comte de Guimerà (I599-1638) — amb una de les biblioteques més completes del seu temps- amb qui havia fundat ${ }^{24}$ i assistit a la famosa Academia

24. Es desconeix la continuïtat d'aquestes reunions més enllà de l'estiu de i608; veg. el ms. 9396 de la Biblioteca Nacional de Madrid, amb els estatuts de la Pítima contra la ociosidad, signats i aprovats per la comtessa 
Verònica Zaragoza Gómez

Sociabilitat i projecció poètica: veus de dones en els certàmens literaris barrocs

Pitima contra la ociosidad (I608). Reunida al palau que el matrimoni posseïa a la localitat aragonesa de Fréscano, l'acadèmia celebrà diversos certàmens a la beatificació de Lluís Beltran, a sant Francesc, a santa Cecília i a santa Agnés, cosa que indicaria que la nostra autora estava avesada a la poètica festiva, amb caràcter commemoratiu religiós. A l'obra Cataluña desengañada: discursos políticos, propaganda política del temps de la Guerra de Successió, Alexandre Ros esmenta la "condesa de Guimerá» com a noble filipista represaliada al costat d'altres dames de llinatges distingits, que resulten familiars en aquestes esferes de sociabilitat nobiliària: Catalina Fernández de Córdoba, duquessa de Cardona; Margarida Teresa d'Erill, comtessa d'Erill (vídua del sard Ignasi de Castellví); Jerònima Lull Cabrera, comtessa de Montagut...(Ros I646: 447-447). Totes elles dones amb «un importante papel como transmisoras de patrimonios nobiliarios y algunas se vieron proyectadas, como doña Catalina, a la primera línea de la actividad política» (Molas 2004b: I43).

De fet, les altres dames presents en aquest certamen de 1656 són totes de bona soca: Mariana Llupià i Grimau, possiblement Mariana Maria Magdalena de Llupià i Pagés, filla de Joan de Llupià i Saragossa, procurador reial del Rosselló i de la Cerdanya (I625), i vídua d'Aleix de Grimau i de Vilafranca; Maria de Lara i Guzman, de possible ascendència familiar castellana; Maria de Perapertusa-Vilademany (?, I636- ?, I660), «dama muy cumplida» (Modolell I656: 156) i guanyadora d'un dels premis, filla d'Antoni de Perapertusa i de Vilademany, vescomte de Jóc, al Rosselló, i baró de Taradell i Viladrau, la qual es casaria tres anys després amb l'aristòcrata Jean François de Bournonville, mestre de camp a Catalunya, marqués de Risbourg i descendent de la més alta noblesa de Flandes i França; Maria Gràcia de Pinós, ${ }^{25}$ que podria estar emparentada (germana?) amb Josep Galceran de Pinós i de Perapertusa, baró de Santa Maria de Barberà i castlà d'Arraona, hereu de Francesc Galceran de Pinós-Santcliment i de Corbera, partidari filipista; o Maria Sans i Puig, possiblement Maria Puig i Quintana, casada amb Lluís de Sans i Sans, noble participant a les corts el I626 i I640 (i mare de Francesc de Sans i de Puig, participant en el mateix certamen), que va resultar guanyadora del primer premi «por el romance burlesco / tan de veras acertado", en la categoria de versos en català, en què també van concórrer Maria de Grimau (potser Mariana Grimau, participant en un altre certamen de l'època) i Maria d'Oms, emparentada amb un llinatge ennoblit del Rosselló. La coincidència

de Guimerà i la seua mare, la comtessa d'Erill (Cecília de Sentmenat i d'Alertorn). Tot i la presència del nom d'aquestes dames aristocràtiques en els estatuts de l'acadèmia, llur compareixença es perd en el quadern: una de les poques mencions a Isabel Agnés la trobem en una nota elaborada pel seu marit que l'esmenta com a Isbella. 25. «hizo ostentación gallarda / de sutiles pensamientos» $\mathrm{i}$ «con peregrina gracia / esmeró en conceto y metro» (Modolell 1656: I76 i i84), raó per la qual es va emportar un primer premi. 
de l'antropònim Maria en totes elles fa preguntar-nos si, en efecte, la feminització del tema fou un dels factors d'implicació de tantes dames en aquesta festa poètica. Hi aportaven distinció i, de retruc, n'eixien prestigiades:

$\quad$ Ni faltaron bellas damas
que, discretas, advirtiendo
ser el blanco una matrona
de tan divino festejo,
$\quad$ de su honor más que el sol claro
a la defensa salieron
contra un infierno irritado
con generoso denuedo.

$\mathrm{Al}$ costat d'aquests cognoms nobles, "quatro escogidos luzeros» de l'ambient monàstic barceloní: les clarisses sor Susanna Ribera (?, I6I4- Barcelona, I688) i sor Teresa Balet i Rifós (Barcelona, I6I9-I683) del convent de Santa Isabel; sor Maria Laura Mas (a. I656-d. I7I2), priora del convent de Jerusalem, i la dominica sor Rafaela Rei Felig (Barcelona, c. I656-I693), del convent de Santa Maria de Montsió. Altres participants ens resulten més difícils de documentar, com ara Anna de Paratges, Maria d'Erill (de conegut llinatge establert a l'Alta Ribagorça), Dorotea de Mendoça o Artemísia Clorídea (amb tota probabilitat, pseudònim amb reminiscències mitològiques, ${ }^{26}$ esmentada com a «Ninfa de las riberas del Llobregat»).

Una ullada ràpida al perfil de les dames en permet d'entreveure un interessant quadre sociopolític, amb importants connexions familiars amb bona part del sector aristocràtic català fidel a Felip IV, com acabem de veure (Erill, Llull, Folch de Cardona, Pinós, Perapertusa...). I aquest fet no és, precisament, casual: en una data molt propera al final de la Guerra dels Segadors (acabada teòricament quatre anys abans) i amb bona part de la intel.lectualitat profrancesa desapareguda de l'escena política i cultural catalana, la marcada representació d'aquesta elit en la festivitat i el certamen només podia obeir al desplegament d'uns interessos oligàrquics per guanyar-se el favor polític reial i projectar-se socialment en aquella nova situació política emergent després de la guerra. Sense perdre de vista la tradició de certàmens arrelada a la Corona d'Aragó des de l'edat mitjana, el nou signe polític que prengueren les solemnitats (certàmens inclosos) de la Barcelona en la dècada de I652 i I662, es feia evident en el context immediatament posterior a la capitulació de la Ciutat Comtal, examinat per Reza (2008).

26. El nom fictici remet a Artemisa, deessa de la caça, dels animals i de la Lluna, i a Clorídea, divinitat que encarna la primavera.

Caplletra 65 (Tardor, 2018), pp. 15-41 
Verònica Zaragoza Gómez

Sociabilitat i projecció poètica: veus de dones en els certàmens literaris barrocs

Una nova conjuntura sociopolítica traçava el desenvolupament de les commemoracions, «marcadas por una voluntad propagandística promovida por la Corona Castellana para intentar con la unificación de una creencia, la recuperación del prestigio y poderío real» (Reza 2008: 762). La voluntat de transformar la ciutat amb l'enlluernament d'aquelles festes i de convocar els seus ciutadans a la celebració joiosa de la notícia, en un moment tan penós, ${ }^{27}$ respondria al «momento conciliador, en el que las autoridades catalanas se ven presionadas para alinearse a las disposiciones de Felipe IV» (Reza 2008: 766); rerefons que explicaria com aquella demostració festiva podia representar una instrumentalització: la manifestació fefaent de fidelitat monàrquica davant d'un Felip IV que hi apareix representat amb l'aurèola de misericordiós, perdonant «a un rendido» (Reza 2008: 77I-773).

El I66I, la promulgació d'una butlla definitiva que declarava l'antiguitat de la creença i renovava el vot a la Concepció Immaculada de Maria no va ser desaprofitada per les grans urbs peninsulars, que rivalitzarien pels millors festejos; entre aquestes, Barcelona i València, amb els corresponents certàmens en l'entramat festiu que caracteritzaria els anys I662-I665. En revisar les relacions, no deixa de decebre'ns la manca de continuïtat de participació femenina en els certàmens de tradició immaculista; ${ }^{28}$ uns espais de sociabilitat poètica als quals s'havien acollit les dones poetes una dècada abans amb una vitalitat creixent, però que després de 1656 començava a esllanguir-se.

\section{Extensió del rés de santa Eulàlia (Barcelona, I686)}

De fet, hagueren de transcórrer gairebé tres dècades per a trobar nous testimonis de poesia de certamen de dones, quan l'extensió del rés de santa Eulàlia fou motiu de «festivos y majestuosos cultos», amb certamen inclòs, a Barcelona (Festivos [I686]). En aquesta ocasió no és tant la xifra de dames participants el que ens interessa de destacar, només tres, sinó la tipologia i la tria lingüística de les peces aportades, que res té a veure amb el que havia caracteritzat les dinàmiques anteriors: ens referim als

27. Amb l'ocupació militar, Catalunya també va haver de fer front a una forta epidèmia de pesta i a la manca d'aliments, situació al-ludida per Modolell: «Vengan las Musas este año/ a justas con poca ropa. / Las de nuestra triste tierra/ se escusan con responder/ que no pueden ricas ser/tras tantos ańos de guerra. Miserable tiempo en suma...» (I656: I39-I40).

28. Per bé que les dones es van implicar en aquestes festes, segons un manuscrit que les narra: «Domingo a 4 de dicho fue el primer Domingo que estuvo patente el Santíssimo en la Capilla de Ntra. Sra. del Rosario y hizo el docel bordado de su mano Dona Laura de Alagón muger de don Basilio de Castelví governador del presente Reyno y este Domingo hizo y empezó la fiesta dicha sra Gobernadora y buscó otras señoras para los otros primeros Domingos del mes, siendo esta señora la que solicitó y rogó al conde de que todos los primeros domingos estuviesse patente el Santíssimo en dicha Capilla» (cfr. Mas i Usó 2009: 4I6). 
epigrames de Laura d'Alagon, i al dístic de Joana d'Ataide, escrits en llatí. No sabem si l'acostament al canvi de segle i una major preparació de les dames participants degué influir en aquesta tria. No resulta tan estrany, però, que una tercera dama, Caterina de Lara, hi aportés una peça en català.

\section{Tractat de pau de Ryswick (Barcelona, I698)}

Per acabar, la fi de segle va propiciar la celebració d'un dels escassos certàmens organitzats amb motiu d'una commemoració no religiosa: la pau assolida amb el tractat de Ryswick, que posava fi a la Guerra dels Nou Anys (I688-I697). El cessament de setges, ocupacions i hostilitats franceses va ser solemnitzat amb festejos sonats a la capital principatina i amb un certamen poètic que convocava «las ingeniosas Musas del barcelonés Parnasso [...] para que en métricas composiciones desahogassen [...] lo grande de su afecto" (Festivo agradecimento [1698]: I4). El caràcter polític de les celebracions podria explicar l'escassa concurrència de dones, més enllà d'una desconeguda barcelonina, amb un jeroglífic castellà. Considerada aquesta la tipologia «más difícil de los que propuso el edicto [...]» (Festivo agradecimento [1698]: 69) i un dels gèneres poètics més «envitricollats del culteranisme» (Riquer, Comas \& Molas 1986: 549), amb aquesta aportació Maria Eulàlia s'hi va fer un lloc destacat, amb el reconeixement que «[...] Barcelona, si tiene mugeres que son otro Marte para la guerra, tiene para la paz mugeres que son otra Minerva» (Festivo agradecimento [1698]: 69). Tanmateix, aquesta peça suposava la fi d'una tradició fructífera en la visibilització de l'escriptura femenina en el nostre domini, ja que no tornem a documentar cap altre testimoni de poesia de certamen femenina més tardà, fins a la restauració dels Jocs Florals.

\section{CONSIDERACIONS FINALS}

L'objectiu d'aquest article ha estat valorar i comptabilitzar la participació de les dones en els certàmens celebrats a les grans ciutats de l'univers lingüístic català. Hem recuperat una important tradició de poesia de certamen femenina emmarcada sobretot en festejos religiosos, que esdevingueren en ple ambient posttridentíl'escenari perfecte on les dones van poder aportar rimes a la devoció dels sants homenatjats. I, si bé aquest fenomen no revela dades significatives quant al nombre de poetes congregades en cada certamen, així com tampoc una evolució cronològica ascendent, sí que ens ha permés constatar la precocitat de les participacions de les dones a casa nostra. 
Verònica Zaragoza Gómez

Sociabilitat i projecció poètica: veus de dones en els certàmens literaris barrocs

I és que el clima d'efervescència cultural registrat a València en el tombant del segle XVI i en la centúria següent, la van convertir també en un dels primers centres de creació i de difusió de poesia de dones a la península; gràcies en part a la poesia de certamen i, paral-lelament, a l'aparició del subgènere de la poesia laudatòria publicada en preliminars (juntament amb la impressió, el I583, d'un cant poètic interpolat d'anònima autora en l'hagiografia del pare Bertran, esmentat més amunt). D'aquesta manera, mentre que a Saragossa les dones no van començar a implicar-se en certàmens fins al $1608^{29}$ i a Madrid no s'hi registren fins al I6I5 (Baranda 2005: 219), a la capital del Túria, el primer poema aportat per una dona a un certamen data de finals del XVI i s'imprimeix el 1602, obra de sor Bernarda Romero.

No obstant això, malgrat que València es converteix en una de les ciutats peninsulars pioneres en la publicació de poesia circumstancial femenina, aquestes impressions no tenen una línia de continuïtat en el temps ni semblen generar un efecte d'emulació. Dit d'una altra manera: malgrat que la publicació de poesia amb autoria femenina comença a ser una realitat a la València de finals del cinc-cents en els nínxols específicament ocasionals, el fenomen no acaba de consolidar-se en la centúria següent, sinó que evoluciona en progressió irregular. Així, mentre que les mostres de versificació femenina urbana augmenten de manera notable en els certàmens barcelonins, en canvi, no destaquen significativament a València, on no es dóna una correlació directa i proporcional entre la llarga tradició de certàmens documentats i l'impacte i la freqüència de participació de les dones ${ }^{30}$ que resulta més aviat escassa. Ho demostra el fet que entre els catorze certàmens valencians registrats entre 1592 i I668, ${ }^{31}$ únicament hi descobrim deu dones participants. A més, respecte a aquestes dades caldria tenir-hi present que entre les participants n'hi ha una que hi persevera, de vegades en solitari, amb una activitat atestada al llarg de trenta anys. Ens referim a sor Bernarda Romero, participant en sis certàmens valencians entre I592 i I62I. En contraposició al que s'esdevé a València, la major part de les dones apareixen concentrades en els certàmens barcelonins, per als quals hem extret una xifra bastant interessant: un total de setanta-quatre participacions femenines, amb un pic de concurrència significatiu a partir de I6I4, "cuando toda España se volcó en celebrar a la extraordinaria monja de Ávila» (Baranda 2005: 219).

29. Amb un èxit de participació, però, molt per sobre del que documentem a València (Marín 20I3). A més a més, a Granada, el primer poema femení de certamen no veuria la llum fins al I650 (Osuna 2004). 30. Seguim les observacions de Baranda (2005: 218).

3I. Ampliem la llista de certàmens valencians examinada per Martos (20I7) en una panoràmica general sobre el fenomen de participació femenina en aquests espais socioliteraris. 
Si ens centrem en l'extens corpus poètic de dones, respecte a la llengua d'escriptura, no cal dir que depén de les categories a les quals es presentaven els versos. Amb tot, el castellà hi és present de manera predominant, amb versos cultes, condicionats per la temàtica devota i el component d'exalçament dels certàmens. Només en poques ocasions, les dones deixen aquest to cerimoniós per a conrear poesia en català, en general més burlesca i fresca segons les exigències del cartell (Maria Grimau, Maria d'Oms, Maria Sans i Puig, Adriana Cabanyes o Caterina de Lara). També s'hi fa present la llengua llatina, amb caràcter minoritari, amb només dos epigrames presentats en aquesta llengua per dones de les acaballes del XviI.

A més a més, aquest treball ha demostrat la capacitat d'intervenció de les dames (especialment les de les classes privilegiades, nobles i burgeses) en les festivitats urbanes, tant en l'aspecte organitzatiu com, sobretot, participatiu. Amb els perfils culturals que hem pogut establir sobre les autores, possiblement els seus noms poden resultar poc significatius, però la seua presència en aquests espais de sociabilitat literària resulta fonamental com a fenomen de visualització social, per tal com

En ella el nombre se convierte en presencia, y la nómina, en incuestionable realidad, cuyo número es un argumento más de su relevancia social y de las relaciones de "socorros mutuos" que, al menos en un primer momento, pueden establecer entre ellos, además de insertarse en una tradición de la que paulatinamente se proclaman legítimos herederos, en un juego de prestigio en el que el legado va dejando paso a la conquista. (Ruiz Pérez 20II: 384; apud. Marín 20I3: I5I)

En el marc d'aquestes grans festivitats, doncs, l'element de distinció que suposava participar en esdeveniments de gran abast com els certàmens, explicaria un aspecte que, per força, s'ha de tenir present a l'hora de valorar el fenomen: la possibilitat que alguns homes hi presentassen versos amb la signatura d'una dona, a fi de donar-li notorietat i renom en aquestes festes literàries que reunien la flor i nata de la societat de l'època. ${ }^{32}$ S'haurà de tornar a aquesta qüestió sobre la qual no es pot generalitzar, amb la interrogació de noves fonts, hui desconegudes.

Del que no hi ha cap mena de dubte és que les dones van saber aprofitar els intersticis de la festa per a donar a conéixer els seus noms vinculats als esdeveniments socioliteraris més importants de la vida cultural del moment. En efecte: el caràcter extraordinari d'aquestes manifestacions poètiques femenines no hauria d'invalidar la importància del fet que, per primer cop, creadores de poesia ens són conegudes amb nom i cognoms, associats a aquest fenomen urbà. Al capdavall, aquí radica la importàn-

32. Un testimoni revelador l'aporta el manuscrit poètic de Jeroni Vilar amb un conjunt de composicions escrites per a dones destinades a un certamen celebrat a Vic el I6I8.

Caplletra 65 (Tardor, 2018), pp. 15-41 
Verònica Zaragoza Gómez

Sociabilitat i projecció poètica: veus de dones en els certàmens literaris barrocs

cia d'aquestes plataformes de sociabilitat literària per a l'avenç en la visibilitat autorial de les escriptores de la primera modernitat: les impressions femenines augmenten i la dona creadora esdevé cada cop una realitat més possible (Martos 20I7). Tanmateix, quan aquesta tradició dels certàmens perd vitalitat, a les darreries del segle XVII, les dones quedaran orfes de les infraestructures necessàries per a fer-se sentir (Marín 20I3: 153). La desaparició dels certàmens suposà la clausura d'una època daurada per a la visibilitat social de la poesia (o, encara més, la creació literària) femenina, en la mesura que les dones van deixar de tenir un espai per a la creativitat poètica i la impressió dels seus versos, i foren reduïdes dramàticament llurs possibilitats de consolidar-se en els espais literaris. En el segle XviıI, les aportacions de les dones foren reduïdes a l'ostracisme conventual o a l'escriptura privada. Haurien d'esperar al segle xIx per a trobar nous canals d'expressió poètica legítims amb els Jocs Florals restaurats, que van representar, també per a elles l'emergència d'una «supervivència soterrada».

Verònica Zaragoza Gómez Universitat de València veronica.zaragoza@uv.es ORCID 0000-0003-4408-2717 


\section{ANNEX. CERTÀMENS DEL DOMINI LINGÜÍSTIC CATALÀ AMB PARTICIPACIÓ FEMENINA (S. XVI-XVII) ${ }^{33}$}

\begin{tabular}{|c|c|c|c|c|}
\hline$A_{N Y}$ & LLOC & EFEMÈRIDE & EDICIÓ & Participants \\
\hline 1532 & València & $\begin{array}{l}\text { Immaculada } \\
\text { Concepció }\end{array}$ & $\begin{array}{l}\text { [Obres... en lahor y glòria de la Inma- } \\
\text { culada Concepció de la Puríssima Mare } \\
\text { de Déu], València, Francisco Romano, } \\
1533 .\end{array}$ & \\
\hline 1580 & Barcelona & $\begin{array}{l}\text { Immortalitat de } \\
\text { l'ànima }\end{array}$ & $\begin{array}{l}\text { Gayetá VIDAL y VALENCIANO (ed.), } \\
\text { Libell de la Inmortalitat de l'ánima } \\
\text { nostra, Barcelona, Folletí de “La Re- } \\
\text { naxensa”, Estampa de L. Obradors y P. } \\
\text { Sulé, } 1872 .\end{array}$ & \\
\hline $\begin{array}{l}\text { c. } \\
1592- \\
1593\end{array}$ & València & $\begin{array}{l}\text { Org. per Bernat } \\
\text { Català de Vale- } \\
\text { riola }\end{array}$ & $\begin{array}{l}\text { Justas poéticas hechas a la devoción de d. } \\
\text { Bernardo Catalán de Valeriola, València, } \\
\text { Juan Crisòstomo Gàrriz, } 1602 \text {. }\end{array}$ & $\begin{array}{l}3 \text { cert: 2) sor Bernarda } \\
\text { Romero (II); 3) sor } \\
\text { Bernarda Romero (I) } \\
\text { i ([I]) }\end{array}$ \\
\hline 1600 & València & $\begin{array}{l}\text { Translació de } \\
\text { relíquia de sant } \\
\text { Vicent Ferrer }\end{array}$ & $\begin{array}{l}\text { Francisco TÁRREGA, Relación de las Fies- } \\
\text { tas que el arçobispo y cabildo de Valencia } \\
\text { hizieron en la translación de la reliquia } \\
\text { del glorioso S. Vincente Ferrer a este santo } \\
\text { templo..., València, Pedro Patricio Mey, } \\
1600 .\end{array}$ & \\
\hline 1601 & Barcelona & $\begin{array}{l}\text { Canonització } \\
\text { de Ramon de } \\
\text { Penyafort }\end{array}$ & $\begin{array}{l}\text { Jaime ReBullosa, Relación de las } \\
\text { grandes fiestas que en esta ciudad de } \\
\text { Barcelona se han echo a la canonización } \\
\text { de su hijo san Ramon de Peñafort, de la } \\
\text { orden de predicadores, Barcelona, Jayme } \\
\text { Cendrat, } 1601 .\end{array}$ & $\begin{array}{l}2 \text { cert.: 1) religiosa anò- } \\
\text { nima (I) i 2) Caterina } \\
\text { de Cardona (I); 'dama } \\
\text { Figuerola' ([I]); 'Ollera' } \\
\text { ([I]); 'Boscana' ([I]); } \\
\text { 'dama cathalana' ([I]); } \\
\text { 'Leonarda' ([I]); 'nimpha } \\
\text { Astora' ([I]); 'Alburquer- } \\
\text { 'que' ([I]); 'Jori' ([I]); } \\
\text { 'Fontelles' ([I]) }\end{array}$ \\
\hline 1602 & València & $\begin{array}{l}\text { Canonització } \\
\text { de Ramon de } \\
\text { Penyafort }\end{array}$ & $\begin{array}{l}\text { Vicente Gómez, Relación de las famo- } \\
\text { sas fiestas que hizo la ciudad de Valencia } \\
\text { a la canonización del bienaventurado } \\
\text { S. Raymundo de Peñafort..., València, } \\
\text { Juan Crisóstomo Gárriz, } 1602 \text {. }\end{array}$ & $\begin{array}{l}\text { sor Bernarda Romero } \\
\text { (II) }\end{array}$ \\
\hline
\end{tabular}

33. La llista fa referència als certàmens impresos; entre parèntesis remetem als poemes presentats al certamen; quan es troba entre claudàtors, significa que només ens ha arribat la menció de participació al vexamen o sentència. 
Verònica Zaragoza Gómez

Sociabilitat i projecció poètica: veus de dones en els certàmens literaris barrocs

\begin{tabular}{|c|c|c|c|c|}
\hline 1606 & València & $\begin{array}{l}\text { Domènec } \\
\text { d'Anadó }\end{array}$ & $\begin{array}{l}\text { Vicente Gómez, Verdadera relación de } \\
\text { la vida, muerte y hechos milagrosos del } \\
\text { bendito p.f. Domingo Anadón..., Va- } \\
\text { lència, [s.e.], } 1607 .\end{array}$ & $\begin{array}{l}\text { sor Bernarda Romero } \\
\text { (II) }\end{array}$ \\
\hline 1608 & València & $\begin{array}{l}\text { Beatificació de } \\
\text { Lluís Bertran }\end{array}$ & $\begin{array}{l}\text { Gaspar Aguilar, Fiestas que la insigne } \\
\text { ciudad de Valencia ha hecho por la } \\
\text { beatificación del santo fray Luys Bertrán, } \\
\text { València, Pedro Patricio Mey, } 1608 . \\
\text { Vicente Gómez Los sermones y fiestas } \\
\text { que la ciudad de Valencia hizo por la } \\
\text { beatificación del glorioso padre San Luýs } \\
\text { Bertrán, València, Juan Crisóstomo } \\
\text { Gárriz, } 1609 .\end{array}$ & $\begin{array}{l}\text { Bernarda Romero (I); } \\
\text { Bàrbara Abarca (I); } \\
\text { Esperança Abarca (I); } \\
\text { dama devota (I); sor } \\
\text { Àngela Sànchez (I) }\end{array}$ \\
\hline 1614 & València & $\begin{array}{l}\text { Beatificació de } \\
\text { Teresa de Jesús }\end{array}$ & $\begin{array}{l}\text { Fray Diego de San José, Compendio de } \\
\text { las solenes fiestas que en toda España se } \\
\text { hicieron en la beatificación de N.M.S. } \\
\text { Teresa de Jesús..., Madrid, Viuda } \\
\text { d'Alonso Martín, } 1615 .\end{array}$ & sor Jacinta Herèdia (I) \\
\hline 1614 & Barcelona & $\begin{array}{l}\text { Beatificació de } \\
\text { Teresa de Jesús }\end{array}$ & $\begin{array}{l}\text { Josep Dalmau, Relación de la solem- } \\
\text { nidad con que se han celebrado en la } \\
\text { ciudad de Barcelona las fiestas a la } \\
\text { beatificación de la Madre S. Teresa de } \\
\text { Jesús..., Barcelona, Sebastián Matevad, } \\
1615 .\end{array}$ & $\begin{array}{l}\text { Lucrècia Dalmau (I); } \\
\text { sor Elena de Cardona } \\
\text { (I); Teresa del Calvari } \\
\text { (I); Graïda de Blanes i } \\
\text { Tamarit (Graïda Pinós) } \\
\text { (III); Anna Magdalena } \\
\text { de Tamarit i Guardiola } \\
\text { (I); sor Teresa Preixana } \\
\text { (I); Francesca Toledo } \\
\text { (I); Anna Ivorra i Raset } \\
\text { (Anna Meca) (I); Joana } \\
\text { o Teresa Enríquez (I); } \\
\text { sor Joana Ferran (I) }\end{array}$ \\
\hline 1619 & València & $\begin{array}{l}\text { Tomàs de Villa- } \\
\text { nueva }\end{array}$ & $\begin{array}{l}\text { Jerónimo MARTÍNEZ DE LA VEGA, } \\
\text { Solenes i grandiosas fiestas, que la noble } \\
\text { i leal ciudad de Valencia a echo por la } \\
\text { beatificación de su santo pastor i padre } \\
\text { D. Tomás de Villanueva, València, } \\
\text { Felipe Mey, } 1620 .\end{array}$ & $\begin{array}{l}\text { sor Bernarda Romero } \\
\text { ([I]) }\end{array}$ \\
\hline 1619 & Barcelona & $\begin{array}{l}\text { Immaculada } \\
\text { Concepció }\end{array}$ & $\begin{array}{l}\text { Vicente de Moradell, Sentencia poé- } \\
\text { tica al certamen publicado a la Inma- } \\
\text { culada Concepción de nuestra Senyora, } \\
\text { Barcelona, Gerónimo Margarit, } 1619 .\end{array}$ & $\begin{array}{l}\text { Adriana Cabanyas i Si- } \\
\text { nisterra (I); Isabel Boix } \\
\text { (I); Casilda de Villalba } \\
\text { (I); Jerònima Llull i } \\
\text { Cabrera (I); Francesca } \\
\text { Escalàs ([I]) }\end{array}$ \\
\hline
\end{tabular}




\begin{tabular}{|c|c|c|c|c|}
\hline 1621 & València & Teresa de Jesús & $\begin{array}{l}\text { Manuel Mendoza, Fiestas que el } \\
\text { convento de nuestra Señora del Carmen } \\
\text { de Valencia hizo a nuestra santa madre } \\
\text { Teresa de Jesús, València, Felipe Mey, } \\
1622 .\end{array}$ & $\begin{array}{l}\text { sor Emerenciana d'Haro } \\
\text { (I), sor Bernarda Rome- } \\
\text { ro (I), sor Eugènia Pérez } \\
\text { (I), 'Dońa Laura' ([I] } \\
\text { vexamen); sor Felicitas } \\
\text { Amada ([I]) }\end{array}$ \\
\hline 1622 & València & $\begin{array}{l}\text { Immaculada } \\
\text { Concepció }\end{array}$ & $\begin{array}{l}\text { Juan N. CRehuades, Solenes y gran- } \\
\text { diosas fiestas que la noble y leal ciudad } \\
\text { de Valencia ha hecho por el nuevo } \\
\text { decreto que la santidad de Gregorio XV } \\
\text { ha concedido en favor de la Immacula- } \\
\text { da Concepción de Maria..., València, } \\
\text { Pedro Patricio Mey, } 1623 .\end{array}$ & $\begin{array}{l}\text { sor Francisca Sans } \mathrm{Na}- \\
\text { varro }([\mathrm{I}])\end{array}$ \\
\hline 1622 & Girona & $\begin{array}{l}\text { Canonització } \\
\text { d'Ignasi de } \\
\text { Loiola, Francesc } \\
\text { Xavier i beati- } \\
\text { ficació de Lluís } \\
\text { Gonzaga }\end{array}$ & $\begin{array}{l}\text { Francisco RuIz, Relación de las fiestas } \\
\text { que hizo el colegio de la Conpañia de } \\
\text { Jesús de Girona. En la canonización de } \\
\text { sv patriarca san Ignacio i del apóstol } \\
\text { de la India san Francisco Xavier; } i \\
\text { beatificación del angélico Lvís Gonzaga, } \\
\text { Barcelona, Sebastian y Jaime Matevad, } \\
1623 \text {. }\end{array}$ & $\begin{array}{l}\text { Elvira Sarriera (I), Ma- } \\
\text { ria Samsó (I), Francisca } \\
\text { Agullana (I), Magdalena } \\
\text { Agullana (I), Maria de } \\
\text { Llupià (I), Artemísia } \\
\text { Samsó (I), Agnés Real } \\
\text { de Fontclara (I), Oròsia } \\
\text { d'Agullana (I) }\end{array}$ \\
\hline 1623 & València & Sant Lluc & $\begin{array}{l}\text { Francesc Cros, Fiestas que en la insig- } \\
\text { ne universidad de Valencia se celebran } \\
\text { del glorioso doct. y evangelista s. Lucas, } \\
\text { València, Miquel Sorolla, } 1626 .\end{array}$ & \\
\hline 1625 & Palma & $\begin{array}{l}\text { Caterina Tomàs } \\
\text { i Gallard }\end{array}$ & $\begin{array}{l}\text { Miquel Tomàs, Certamen poético, en } \\
\text { honor de la venerable madre sor Cat- } \\
\text { harina Thomasa mallorquina, monja } \\
\text { canóniga reglar de san Agustín, man- } \\
\text { tenido en la isla y ciudad de Mallorca, } \\
\text { Barcelona, Gabriel Nogués, } 1636 .\end{array}$ & \\
\hline 1626 & Barcelona & $\begin{array}{l}\text { Canonització } \\
\text { de Ramon de } \\
\text { Penyafort }\end{array}$ & $\begin{array}{l}\text { Joan Batista FELICES DE CÁCERES, } \\
\text { Sentencia en la armada poética, propu- } \\
\text { esta y premiada por la insigne ciudad de } \\
\text { Barcelona, en honra de su hijo y Padre } \\
\text { San Ramón de Peñafort. Dirigida al } \\
\text { mismo santo. [...] Con el Vexamen } \\
\text { catalán gracioso de micer Pedro Antonio } \\
\text { Iofreu, Barcelona: Sebastián y Jaime } \\
\text { Matevad, 1626. } \\
\text { [Sentència acèfala, dins Baptista } \\
\text { Mirambell, Recreo i jardi del Parnàs } i \\
\text { muses catalanes, Biblioteca de Catalu- } \\
\text { nya, Ms. 1358, f. 273-281] }\end{array}$ & $\begin{array}{l}\text { Jerònima Castro, Leticia } \\
\text { Pibernat, Alexandra } \\
\text { Leòncia Izquierdo } \\
\text { (o Esquerdo), Maria } \\
\text { d'Henares, Maria Pa- } \\
\text { llarols, Lluïsa Henares, } \\
\text { Isabel Margarit, Maria } \\
\text { d'Aguiló, Magdalena } \\
\text { Serra, Petronila de } \\
\text { Lobera. }\end{array}$ \\
\hline
\end{tabular}


Verònica Zaragoza Gómez

Sociabilitat i projecció poètica: veus de dones en els certàmens literaris barrocs

\begin{tabular}{|c|c|c|c|c|}
\hline 1656 & Barcelona & $\begin{array}{l}\text { Immaculada } \\
\text { Concepció }\end{array}$ & $\begin{array}{l}\text { Francesc Modolell I Costa, Justa } \\
\text { poética consagrada a las festivas glorias } \\
\text { de María en su Immaculada Concep- } \\
\text { ción mantenida en la parroquial iglesia } \\
\text { de Santa María del Mar de la ciudad } \\
\text { de Barcelona, Barcelona, Narcís Casas, } \\
1656 .\end{array}$ & $\begin{array}{l}\text { Isabel Agnés d'Erill } \\
\text { (comtessa de Guimerà) } \\
\text { (II), Mariana Llupià i } \\
\text { Grimau (I), Maria de } \\
\text { Lara i Guzman (I), Ma- } \\
\text { ria de Perapertusa i Vi- } \\
\text { lademany (I), Dorotea } \\
\text { de Mendoza (I), Maria } \\
\text { d'Erill (I), Maria Sans i } \\
\text { Puig (I), Maria de Gri- } \\
\text { mau (I), Maria d'Oms } \\
\text { (I), Maria Gràcia de } \\
\text { Pinós (I), (Maria ¿?) de } \\
\text { Luna ([I]), Artemísia } \\
\text { Clorídea (I), sor Teresa } \\
\text { Balet (I), sor Rafaela } \\
\text { Rei Felig (I), sor Maria } \\
\text { Laura (I), sor Susana } \\
\text { Ribera (II), sor Anna de } \\
\text { Paratges ([I]) }\end{array}$ \\
\hline 1662 & Barcelona & $\begin{array}{l}\text { Immaculada } \\
\text { Concepció }\end{array}$ & $\begin{array}{l}\text { Magestuosa selebridad que en aplausos } \\
\text { festivos consagra el zelo de la augusta y } \\
\text { noble ciudad de Barcelona a la nueva } \\
\text { declaración que la santidad de Alexan- } \\
\text { dro séptimo a dado en su constitución } \\
\text { apostólica, Barcelona, Maria Jalabert, } \\
1662 .\end{array}$ & \\
\hline 1665 & València & $\begin{array}{l}\text { Immaculada } \\
\text { Concepció }\end{array}$ & $\begin{array}{l}\text { Francisco De la Torre y Sevil, Luzes } \\
\text { de la aurora, días de sol, en fiestas de } \\
\text { la que es sol de los dias y aurora de las } \\
\text { luzes María santíssima. Motivadas por } \\
\text { el nuevo indulto de Alexandro Séptimo, } \\
\text { que concede octava con precepto de rezo } \\
\text { de la Inmaculada Concepción, València, } \\
\text { Gerónimo Vilagrasa, } 1665 \text {. }\end{array}$ & \\
\hline 1667 & València & $\begin{array}{l}\text { Mare de Déu } \\
\text { dels Desempa- } \\
\text { rats }\end{array}$ & $\begin{array}{l}\text { Francisco De LA TORRE y SEVIL, Re- } \\
\text { ales fiestas que dispuso la noble, insige } \\
\text { coronada y siempre leal ciudad de Va- } \\
\text { lencia, a honor de la milagrosa imagen } \\
\text { de la Virgen de los Desamparados en la } \\
\text { traslación a su nueva sumptuosa capilla, } \\
\text { València, Gerónimo Vilagrasa, } 1667 .\end{array}$ & \\
\hline
\end{tabular}




\begin{tabular}{|c|c|c|c|c|}
\hline 1668 & València & $\begin{array}{l}\text { Sant Joan de } \\
\text { Mata i sant } \\
\text { Feliu de Valois }\end{array}$ & $\begin{array}{l}\text { José RodríGUEz, Sacro y solemne } \\
\text { novenario, públicas y luzidas fiestas que } \\
\text { hizo el real convento de Nuestra Señora } \\
\text { del Remedio de la ciudad de Valencia, a } \\
\text { sus dos gloriosos patriarcas, san Juan de } \\
\text { Mata y san Félix de Valois..., València, } \\
\text { Benito Macé, } 1669 \text {. }\end{array}$ & \\
\hline 1686 & Barcelona & Santa Eulàlia & $\begin{array}{l}\text { Festivos y magestuosos cultos que la } \\
\text { nobilissima y muy illustre ciudad de } \\
\text { Barcelona en } 23 \text { y } 30 \text { de octubre } 1686 \\
\text { dedicó a su inclita hija, patrona, virgen } \\
\text { y protomártyr santa Eulalia, Barcelona: } \\
\text { Jaume Caís [1686]. }\end{array}$ & $\begin{array}{l}\text { Laura Alagon (I), Juana } \\
\text { Ataide (I), Caterina de } \\
\text { Lara (I). }\end{array}$ \\
\hline 1697 & Barcelona & Pau de Ryswick & $\begin{array}{l}\text { Festivo agradecimento, que por la alegre } \\
\text { conclusión de la paz universal de la } \\
\text { Monarquia de España, con las demás } \\
\text { coronas y principes christianos, rindió a } \\
\text { la Magestad de Dios, la excelentíssima } \\
\text { ciudad de Barcelona, Barcelona: Tomás } \\
\text { Loriente, [1698]. }\end{array}$ & Eulàlia Marcer (I) \\
\hline
\end{tabular}

\section{REFERÈNCIES BIBLIOGRÀFIQUES}

Asociación (1972) Asociación Literaria de Gerona, Certamen literario, Girona, Manuel Llach.

BARANDA, N. (2004) «Reflexiones en torno a una metodología para el estudio de las mujeres escritoras en justas del Siglo de Oro», dins M. L. Lobato \& F. Domínguez (eds.), Memoria de la palabra. Actas del VI Congreso de la Asociación Internacional Siglo de Oro, I, Madrid / Frankfurt am Main, Iberoamericana/ Vervuert, pp. 307-316.

- (2005) Cortejo a lo prohibido. Lectoras y escritoras en la España moderna, Madrid, Arco/Libros.

Brown, K. (1987) "Context i text del Vexamen d'acadèmia de Francesc Fontanella», Llengua \& Literatura, 2, pp. 173-252.

- (I993) «María de Zayas y Sotomayor: Escribiendo poesía en Barcelona en época de guerra (I643)», DICENDA. Cuadernos de Filología Hispánica, II, pp. 355-360.

Busquets, J. (1994) La Catalunya del Barroc vista des de Girona: la crònica de Jeroni de Real (I626-I683), Barcelona, Publicacions de l'Abadia de Montserrat, 2 vol. 
Verònica Zaragoza Gómez

Sociabilitat i projecció poètica: veus de dones en els certàmens literaris barrocs

Corbera, E. (1629) Vida i echos maravillosos de doña María de Cervellón, llamada Maria Socós, beata professa del Orden de nuestra Señora de la Merced Redención de Cautivos..., Barcelona, Pedro Lacavalleria.

De la Cruz, M. (1627) España restaurada en Aragón por el valor de las mugeres de Jaca i sangre de santa Orosia..., Saragossa, Pedro Cabarte.

Ferrando, A. (1983) Elscertàmens poètics valencians del segle XIV al XIX, València, Alfons el Magnànim.

García Espuche, A. et al. (2010) Festes i celebracions. Barcelona, I70o, Barcelona, Ajuntament.

Marín, M. C. (20I3) «Los certámenes poéticos aragoneses del siglo XviI como espacio literario de sociabilidad femenina», Bulletin Hispanique, II5/I, pp. I45-164.

Martos Pérez, M. D. (20I7) «Visibilidad autorial y competencia de las escritoras en justas poéticas de la primera Edad Moderna española», Calíope, 22/2, pp. 63-99.

Mas I Usó, P. (2009) Justas valencianas barrocas, València, Biblioteca Valenciana.

Mínguez, V., P. González, \& I. Rodríguez (20IO) Fiesta Barroca. El Reino de Valencia (I599-I802), Castelló de la Plana, Universitat Jaume I.

Miró, M. M., ed. (1995) La poesia de Francesc Fontanella, Barcelona, Curial.

Molas, P. (2004a) «Dames del Barroc», Pedralbes, 24, pp. I83-204.

- (2004b) «La Duquesa de Cardona en I640», Cuadernos de Historia Moderna, 29, pp. I33-I43.

Monteagudo, M. P. (2004) «La ciudad, escenario de la fiesta política en el Antiguo Régimen", dins P. Martínez-Burgos \& A. Rodríguez (coord.), La fiesta en el mundo hispánico, Conca, Universidad de Castilla-La Mancha, pp. 32I-350.

Moreno, P. (2002) «El primer comte de Guimerà: notes biogràfiques, genealògiques i heràldiques", Paratge, I4, pp. I5-30.

Osuna, I. (2004) «Justas poéticas en Granada en el siglo XviI: materiales para su estudio", Criticón, 90, pp. 35-77.

Pedraza, P. (1982) Barroco efimero en Valencia, València, Ajuntament.

RezA, A. (2008) «Devoción inmaculista en Barcelona, I652-I662. Una imagen triunfal de la monarquía hispánica», Pedralbes. Revista d'Història Moderna, 28/I, pp. 76I-778.

RiQuer, M. de (1979) Quinze generacions d'una família catalana, Barcelona, Planeta.

Riquer, M. de, A. Comas \& J. Molas (1986) Historia de la literatura catalana, vol. iv, Barcelona, Ariel.

Rodríguez Rodríguez, M. M. (20I2) «Plets successoris a la casa de Cardona i a les seves baronies valencianes (1576-1679)», Pedralbes, 32, pp. I57-I94.

Ros, A. (1646) Cataluña desengañada. Discursos políticos, Nàpols, Egidio Longo. 
Rossich, A. (2003) «Els certàmens literaris a Barcelona, segles XIV- XVIII», Quaderns d'Història, 9, pp. 83-108.

— (2006) «Els Certàmens: de la Gaia Ciència als Jocs Florals», dins S. Martí (coord.), Actes del Tretzè Col-loqui Internacional de Llengua i Literatura Catalanes, Barcelona, AILLC / Publicacions de l'Abadia de Montserrat, pp. 63-90.

Rossich, A. \& P. Valsalobre (2006) Poesia catalana del barroc. Antologia, Bellcaire d'Empordà, Vitel-la.

Rubió, J. (1985) Història de la literatura catalana, II, Barcelona, Publicacions del'Abadia de Montserrat / Generalitat de Catalunya.

Ruiz Pérez, P. (20II) «La república de los poetas: la trama en los versos», dins Compostella aurea. Actas del VIII Congreso de la Asociación Internacional del Siglo de Oro, I, Santiago de Compostel.la, Universidade de Santiago de Compostela, pp. 383-392.

Saborit, V. (165I) Historia de la vida, virtudes y milagros del Beato Luis Bertrán, València, Bernardo Nogués.

Zaragoza, V. (20I5) “"Cual doctora en cielo graduada...”. La poesia femenina per als certàmens literaris amb motiu de la beatificació i canonització de Teresa de Jesús (València, I6I4 i I62I; Barcelona, I6I4)», SCRIPTA. Revista Internacional de Literatura i Cultura Medieval i Moderna, 6, pp. 251-290.

- (20I6) "En vers vull desafiar...". La poesia femenina a l'àmbit català (segles XVI-XVIII). Edició crítica, tesi doctoral, Universitat de Girona.

— (2017) «Fasto barroco, proyección ciudadana y poesía femenina: la ciudad moderna es (y será) de las mujeres», DIALOGOI. Rivista di studi comparatistici, 4, pp. 37-54.

- [en premsa] «Impresión y legitimación de la escritura femenina en el siglo XvI. A propósito de un canto poético femenino interpolado (Valencia, 1584)», Espacios textuales, Salamanca, SEMYR, 2018. 
